\title{
Articles
}

\section{Effect of Carbon Black Activation on Physicomechanical Properties of Butadiene-nitrile Rubber}

\author{
N. V. Shadrinov, ${ }^{\dagger, *}$ E. A. Kapitonov, ${ }^{\ddagger}$ M. D. Sokolova, ${ }^{\dagger}$ A. A. Okhlopkova, ${ }^{\dagger,+}$ Ee Le Shim,${ }^{\S}$ and Jin-Ho Cho ${ }^{\ddagger, \#, *}$ \\ ${ }^{\dagger}$ Institute of Oil and Gas Problems, the Siberian Branch of Russian Academy of Sciences, Yakutsk 677000, Russia \\ E-mail: NShadrinoff@yandex.ru \\ ${ }^{\star}$ Department of Chemistry, North-Eastern Federal University named after M.K. Ammosov, Yakutsk 677000, Russia \\ ${ }^{\S}$ School of Mechanical and Automotive Engineering, Halla University, Wonju 220-712, Korea \\ "Department of Energy and Biotechnology, Myongji University, Kyunggido 449-728, Korea \\ E-mail: jinhcho@mju.ac.kr \\ Received April 28, 2014, Accepted June 3, 2014
}

\begin{abstract}
The effects of mechanical activation of carbon black on the processing and properties of butadiene nitrile rubber were studied. Mechanical activation of carbon black caused an improvement in the physical and mechanical properties of the butadiene-nitrile rubber, BNR-18AMN. The optimum activation time that would afford rubber with improved properties was established.
\end{abstract}

Key Words : Carbon black, Butadiene-nitrile, Rubber, Mechanical activation

\section{Introduction}

Manufacturing of low-cost but high-quality rubber products has continued to be a challenging but attractive task given its potential benefits. One of the more popular methods to control the physical and mechanical properties of elastomeric materials is the use of dispersed fillers, ${ }^{1}$ which can reduce rubber consumption and have a direct positive influence on its properties. Carbon black is the most commonly used filler owing to its unique reinforcement properties. ${ }^{2-4}$ It is well known that the reinforcing properties of carbon black depend on the size, shape, surface, and chemical properties of its aggregates. ${ }^{5,6}$ However, rubber reinforcement by carbon black has not yet been studied in detail. ${ }^{7}$ At present, despite extensive research on novel methods of reinforcing with carbon black, ${ }^{8-10}$ there are limited studies focusing on improving the physical and mechanical properties of rubber mixes and developing elastomeric materials with application-specific complex properties.

The surface of dispersed fillers can be modified by mechanical activation, preventing agglomeration of particles, increasing their surface activity, and ensuring an even distribution of the filler particles in the polymeric matrix. Recent studies on mechanical activation of dispersed fillers revealed that they possessed a nonequilibrium energy state. ${ }^{11-14}$ This phenomenon is the result of the energy absorbed during elastic deformation at the material surface. The nonequilibrium energy state of fillers is connected to the following factors: oscillatory excitement of atoms, electronic excitement and ionization, deformation of filler connections, bond angles, electron migration processes, and mass transfer in filler itself. ${ }^{11-14}$ The energy required for mechanical activation of fillers is higher than that required for thermal activation. $^{11}$

\section{Experimental}

Butadiene-nitrile rubber with a low acrylonitrile content $(\mathrm{BNR}-18 \mathrm{AMN})^{15}$ reinforced with activated carbon black filler $(\mathrm{P} 803)^{16}$ was studied. A typical standard order of addition and mixing of the rubber mixture components is as follows. Plastification of BNR is effected in $5 \mathrm{~min}$; subsequent filling of activated carbon black and mixing, simultaneous addition of $\mathrm{ZnO}$ and stearic acid, and the final addition of sulfur and thiazole as the curing group require 10,10 , and $5 \mathrm{~min}$, respectively. BNR-18AMN contains $2.5 \%$ of sulfur, $1.5 \%$ of thiazole, $2.5 \%$ of $\mathrm{ZnO}$, and $50 \%$ of carbon black P803, and $1.5 \%$ of stearic acid. Activation of carbon black using a planetary mill (Activator 2S; JSC Activator, Russia $)^{17}$ was carried out for $0,30,60,90,120$, 150 , and $180 \mathrm{~s}$ at $13{ }^{\circ} \mathrm{C}$. Rotational speeds around the central axis of the drums were $1000 \mathrm{rpm}$ and $1500 \mathrm{rpm}$. Centrifugal acceleration reached $150 \mathrm{G}$. Number of grinding spheres was 40 (160 g). Carbon loading in each drum was $30 \mathrm{~g}$.

In this work, the effect of carbon black activation time on physical and mechanical properties was studied. It is known that the characteristics of carbon black that influence the matrix material properties are its dispersion in the matrix, particle structure, and density. The most important tool for studying the characteristics of carbon black is an electronic microscope. ${ }^{18}$ The structure of carbon black surface before and after mechanical activation was investigated using a 
raster electronic microscope (JEOL JSM 7800F, Japan) operated at $2 \mathrm{~kW}$. The specific surface area of carbon black was investigated using Sorbtometer-M (Russia) ${ }^{19}$ as a function of the extent of activation.

In the manufacture of rubber mixtures, filling of carbon black into rubber is very important because carbon black significantly affects the properties of rubber. ${ }^{18} \mathrm{~A}$ lack of surface activity of carbon black leads to a very poor rubber module, and hence, it is important to study and optimize the process of filling carbon black into rubber. There are two stages in this process: filling of carbon black into rubber, and distribution of carbon black agglomerates in the mixture.

For the first stage of carbon black introduction into rubber, various mechanical activation times were investigated. Mixing was performed on laboratory rollers (Polymix 110L; Brabender, Germany) using a B50EHT mixer (Benberi's oval gential rotors). ${ }^{20}$ Such a rotor is used because it efficiently simulates the processes taking place upon mixing of rubber on rollers. The effect of filling activated carbon black into rubber over different times on the mixing process was investigated to evaluate the plastograms of carbon black.

In this study, the plastic and elastic properties were investigated at Brabender, Germany. The rotation frequency of the rotors and the temperature employed were $40 \mathrm{rpm}$ and 155 ${ }^{\circ} \mathrm{C}$, respectively.

Plates and columns were designed to investigate certain properties of cured rubber containing varying amounts of activated carbon black. All relevant samples for investigation were vulcanized in hydraulic press GT-7014-H10C (ref) for $20 \mathrm{~min}$ at $155^{\circ} \mathrm{C}$. Physical and mechanical characteristics were evaluated according to GOST 270-75 using Type $2^{21}$ samples on a tension testing machine (Shimadzu Autograph). ${ }^{22}$ Wear resistance was evaluated on a machine employing sliding friction (MI-2), details of which are reported elsewhere. ${ }^{23}$ The resistance of cured rubber to extreme environments was investigated in an oil environment using AMG-10, by a method reported elsewhere. ${ }^{24,25}$

\section{Results and Discussion}

Electronic microscopy of the carbon black structure showed that the packing density of carbon black after mechanical activation (Fig. 1(b)) is higher than that before mechanical activation (Fig. 1(a)).

As shown in Figure 1, carbon black agglomerates (Fig. 1(c)) collapsed after mechanical activation, but carbon units remained (Fig. 1(d)). In addition, the size of carbon black particles forming aggregates decreased upon mechanical activation, as a result of milling (Fig. 1(e)). This means that the agglomerates collapse at mechanical activation, while the carbon black skeleton is increased. The carbon black skeleton reveals the number and form of the aggregated particles.

As shown in Figure 2, the decrease in the size of the carbon black particles is indirectly proved as follows: we observed a systematic increase in the specific surface while investigating the surface characteristics of carbon black,

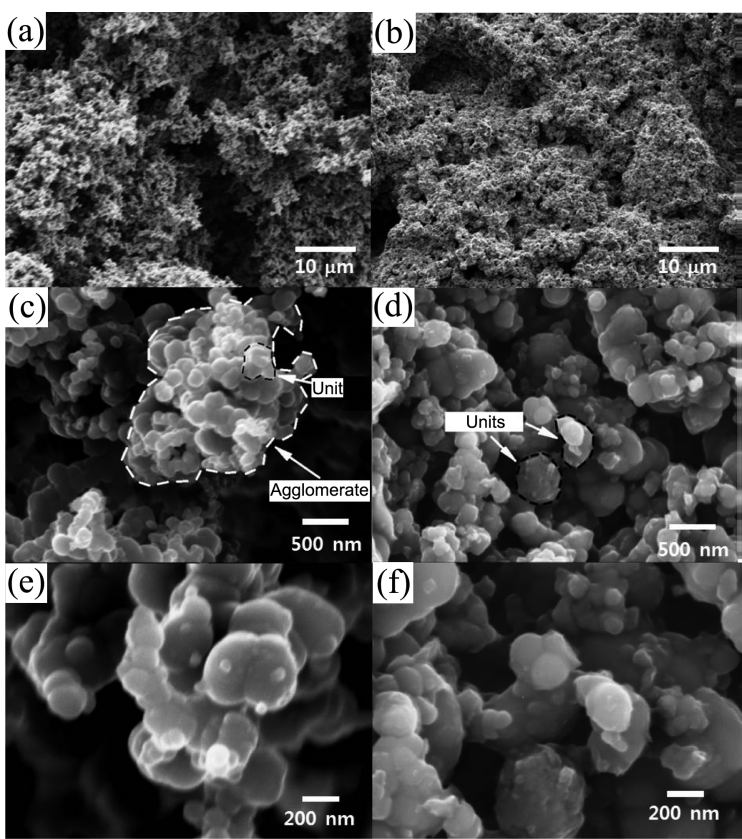

Figure 1. Electronic images of carbon black (a), (c) and (e) before activation and (b) (d) and (f) after mechanical activation for $120 \mathrm{~s}$.

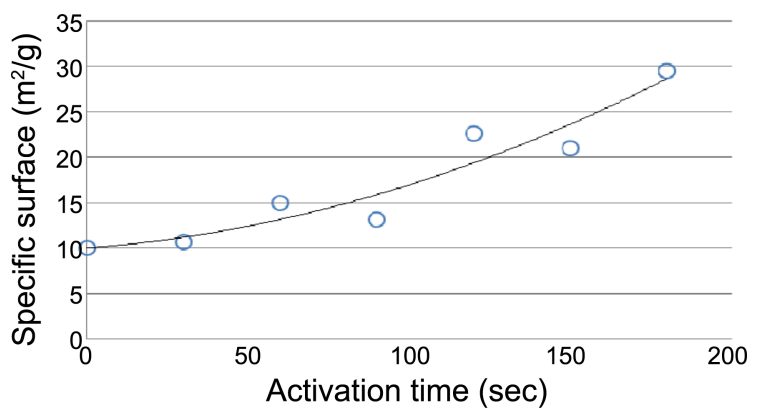

Figure 2. Dependence of the specific surface of carbon black on the duration of mechanical activation.

with respect to activation time. Because the surface area of carbon black corresponds to the interaction with rubber, the specific surface of carbon black increases with a decrease in the size of the carbon black particles.

Besides the two analytical values that characterize carbon black reinforcement of rubber (specific surface and skeleton),

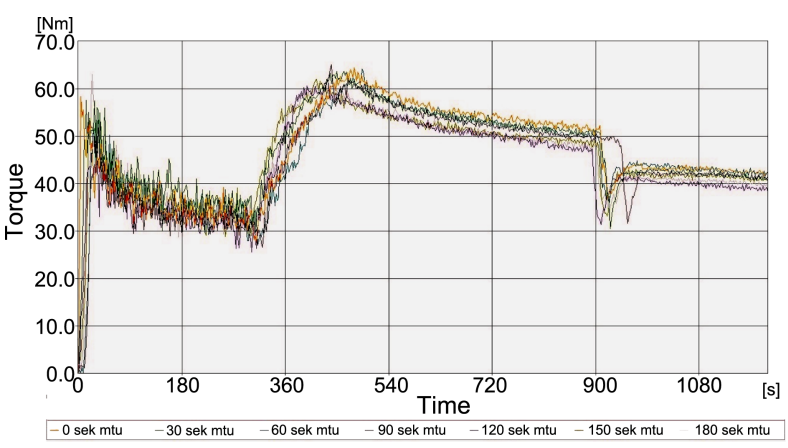

Figure 3. Dependence of viscosity on time of carbon black filling into rubber. 
Table 1. Results of carbon black filling into rubber

\begin{tabular}{lccccccc}
\hline Activation time of carbon black (sec) & 0 & 30 & 60 & 90 & 120 & 150 & 180 \\
Carbon black filling time into rubber (sec.) & 170 & 158 & 152 & 126 & 120 & 110 & 108 \\
Energy (KNm) & 35.9 & 35.2 & 30.3 & 25.6 & 24.4 & 23.3 & 22.7 \\
\hline
\end{tabular}

there is a surface activity that is difficult to measure. ${ }^{6}$ In many respects, surface activity determines the interaction of carbon black with a polymer through physical adsorption and chemisorption. It also has a considerable impact on the physical and mechanical characteristics of rubber filled with activated carbon. As mentioned earlier, mechanical activation destroys agglomerates without destroying aggregate clusters. This leads to an increase in relative elongation, but results in surface activation, leading to an increase in rubber durability.

To determine the speed of mixing or the time required to reach the best mixture, the kinetics of mixing process is very important from a practical perspective. Studies on the mixing process showed that mechanical activation considerably relieves and reduces the time of carbon black filling in rubber. Plastograms (Fig. 3) showed the dependence of viscosity on time for filling carbon black in rubber. This dependence shows the structural changes in rubber for different carbon black activation times. The time interval depicted by two red lines in Figure 3 describes the process of carbon black filling into rubber.

As can be seen in Figure 3, an increase in the carbon black activation time leads to a decrease in viscosity. This considerably relieves rubber processing and decreases the power consumption during the entire manufacturing process. The above process can be explained by the destruction of carbon black during milling. The energy necessary for shear force during carbon black filling in rubber is listed in Table 1 .

As shown in Table 2, the rheological properties indicate an increase in activation time, which leads to an increase in viscosity. The different time indexes of subvulcanization indicate that the mechanical activation of carbon black also influences subvulcanization time. Rubber mix samples created with a long carbon black activation time were characterized by higher values of subvulcanization time. However, a carbon black activation time of $90 \mathrm{~s}$ resulted in the lowest subvulcanization time $(\Delta \mathrm{t}=2 \mathrm{~min})$ and the maximum subvulcanization speed $\left(1 / \Delta \mathrm{t}=0.5 \mathrm{~min}^{-1}\right)$. It is well known ${ }^{6,26,27}$ that the carbon black skeleton influences rubber properties such as viscosity, contraction, and module. An activation time of $90 \mathrm{~s}$ could be necessary for destruction of the agglomerates, while preserving the carbon black aggregates.

The physical and mechanical properties of cured rubber showed that filling rubber with activated carbon black considerably increases the relative elongation of the rubber. Increasing the activation time of carbon black by $30 \mathrm{~s}$ leads to an increase in the relative elongation of rubber by $20 \%$. For example, activation for $30 \mathrm{~s}$ increases the relative rubber elongation from $573 \%$ to $592 \%$, and activation for $60 \mathrm{~s}$ leads to an elongation of $614 \%$. Maximum durability of rubber
Table 2. Comparative properties of rubber mix samples with different carbon black activation times

\begin{tabular}{|c|c|c|c|c|c|c|c|}
\hline \multirow{2}{*}{ Index } & \multicolumn{7}{|c|}{ Composition } \\
\hline & 1 & 2 & 3 & 4 & 5 & 6 & 7 \\
\hline \multicolumn{8}{|c|}{ Rheological properties of rubber mix at $155^{\circ} \mathrm{C}$} \\
\hline $\mathrm{M}_{\max }(\mathrm{N} / \mathrm{m})$ & 31.0 & 30.0 & 29.3 & 30.0 & 29.8 & 29.2 & 29.2 \\
\hline $\mathrm{M}_{\min }(\mathrm{N} / \mathrm{m})$ & 22.1 & 21.9 & 21.4 & 21.6 & 20.7 & 19.8 & 19.9 \\
\hline$t_{\text {initial }}(\min )$ & 1.5 & 1.7 & 1.5 & 1.9 & 2.5 & 2.2 & 2.1 \\
\hline$t_{\text {final }}(\min )$ & 4.4 & 4.7 & 4.2 & 3.9 & 4.7 & 5.3 & 5.4 \\
\hline$\Delta \mathrm{t}(\min )$ & 2.9 & 3.0 & 2.7 & 2.0 & 2.2 & 3.1 & 3.3 \\
\hline $1 / \Delta \mathrm{t}\left(\mathrm{min}^{-1}\right)$ & 0.34 & 0.33 & 0.37 & 0.50 & 0.45 & 0.32 & 0.30 \\
\hline \multicolumn{8}{|c|}{ Rubber properties } \\
\hline$\varepsilon_{\mathrm{p}}(\%)$ & 573 & 592 & 614 & 637 & 660 & 679 & 726 \\
\hline $\mathrm{f}_{\mathrm{p}}(\mathrm{MPa})$ & 11.5 & 12.0 & 12.1 & 12.1 & 11.4 & 11.7 & 10.2 \\
\hline $\mathrm{f}_{400}(\mathrm{MPa})$ & 8.6 & 8.9 & 8.5 & 8.3 & 7.4 & 7.5 & 6.1 \\
\hline$\Delta \mathrm{V}\left(\mathrm{cm}^{3}\right)$ & 0.200 & 0.194 & 0.205 & 0.195 & 0.212 & 0.204 & 0.204 \\
\hline$\Delta \mathrm{Q}(\%)$ & 35.26 & 33.31 & 32.39 & 30.85 & 31.64 & 34.29 & 37.54 \\
\hline $\begin{array}{l}\text { Shore A } \\
\text { (hardness) }\end{array}$ & $57-59$ & $57-58$ & $57-58$ & $55-56$ & $57-58$ & $54-55$ & $56-57$ \\
\hline
\end{tabular}

$\mathrm{M}_{\max }$ : maximum viscosity, $\mathrm{M}_{\min }$ : minimum viscosity, $\mathrm{t}_{\text {initial }}$ : initial subvulcanization time, $\mathrm{t}_{\text {final }}$ : final subvulcanization time, $\Delta \mathrm{t}$ : subvulcanization time, $1 / \Delta \mathrm{t}$ : subvulcanization speed, $\varepsilon_{\mathrm{p}}$ : relative elongation at brake, $\mathrm{f}_{\mathrm{p}}$ : conditional strength at brake, $\mathrm{f}_{400}$ : conditional strength at $400 \%$ elongation, $\Delta \mathrm{V}$ : volume of wear, $\Delta \mathrm{Q}$ : swelling value in AMG-10 oil.

with carbon black activation was obtained for activation times between 60 and $90 \mathrm{~s}$. Activation time longer than $90 \mathrm{~s}$ leads to a decrease in the rubber durability $\left(f_{p}\right.$, and $f_{400}$, ) and Shore A (hardness). The improvement in the rubber elasticity can be explained by the distribution of activated carbon black in the rubber. Improvement of rubber durability with activated carbon black can be explained by the increased surface activity of carbon black. The increase in the carbon black surface activity after mechanical activation occurs is a result of the increase in carbon black specific surface as well as the transfer to the high-excited state. Increased contact between carbon black and rubber leads to increased interaction between them, which in turn leads to rubber reinforcement. Therefore, activation of carbon black for $90 \mathrm{~s}$ is enough to achieve destruction of agglomerates and retain the original carbon black skeleton.

Table 2 shows that abrasive friction of rubber with activated carbon black resulted in a small change volume wear $(\Delta \mathrm{V})$. The best result was obtained from activation of carbon black for $90 \mathrm{~s}$, where the volume wear was $0.195 \mathrm{~cm}^{3}$. In addition, table 2 indicates that rubbers with and without activation of carbon black were swelled in AMG-10 oil. In conclusion, carbon black activation for $90 \mathrm{~s}$ led to a gradual swelling decrease, but activation times longer than $90 \mathrm{~s}$ led to a gradual 
swelling increase.

\section{Conclusion}

Mechanical activation of carbon black (P803) on a planetary mill generated aggregates containing carbon black particles through the destruction of agglomerates. It also led to a decrease in the size of the carbon black particles and subsequently an increase in the specific surface of the carbon black particles. This eventually resulted in more frequent interaction with rubber. This method of carbon black activation in the process of manufacturing butadiene-nitrile rubber can improve the physical and mechanical properties of the rubber. A carbon black activation time of $90 \mathrm{~s}$ was optimum for obtaining rubber with improved physical and mechanical properties as well as excellent wear/oil resistance.

Acknowledgments. This research was supported by the Russian Foundation for Basic Research (RFBR Grant 09-0398504-p_East_a) and a grant from the Fundamental R\&D Program for Core Technology of Materials funded by the Ministry of Knowledge and Economy, Republic of Korea.

\section{References}

1. García, C.; Monserrat de la Luz, M. Polymer-Inorganic Nanocomposites: Influence of Colloidal Silica; Print Partners Ipskamp B.V.: Enschede, 2004; pp 13-16.

2. Ganguly, S.; Bhattacharya, P.; Banerjee, A. N. Indian J. Chem. Tech. 2005, 12, 695.

3. Ososhnik, N. A.; Shutilin, Y. F.; Karmanova, O. V. Manufacturing of Rubber Technical Products Manual; Voronez: 2007; p 117.

4. Reznichenko, S. V.; Morozova, Y. L. Big Reference Book of a Rubber Scientist; P. 1. Rubber and Ingredients; Techinform MAI: Moscow, 2012; p 527.

5. Zhou, X. W.; Zhu, Y. F.; Liang, J. Mater. Res. Bull. 2007, 42, 456.

6. Dick, J. S. Rubber Technology; Compoundicng and Testing for Performance-Carl Hanser Verlag: Munich, 2001.

7. Jha, V. Carbon Black Filler Reinforcement of Elastomers; PhD Thesis, London, 2008; pp 26-27.

8. Al-Hartomy, O. A.; Al-Solamy, F.; Al-Ghamdi, A.; Dishovsky, N.; Ivanov, M.; Mihaylov, M.; El-Tantawy, F. Inter. J. Polymer
Sci. 2011, 2011, 1.

9. Malinova, P.; Nikolov, R.; Dishovski, N.; Lakov, L. Kautschuk \& Gummi Kunstst 2004, 57, 443.

10. Ao, G.; Hu, Q.; Kim, M.-S. Carbon Lett. 2008, 9, 115.

11. Avvakumov, E. G.; Karakachev, L. G. Chemistry for Substainable Development 2004, 12, 287-291.

12. Butyagin, P. U. Chemistry Achievements 1994, 63, 1031.

13. Wieczorek-Ciurowa, K.; Gamrat, K. Materials Science 2007, 25 , 219.

14. Avvakumov, E.; Senna, M.; Kosova, N. Some Theoretical Aspects of Mechanochemical Reactions; Soft Mechanochemical Synthesis: A Basis for New Chemical Technologies; Kluwer: New York, 2002.

15. We purchased butadiene-nitrile rubber from JCS "KVART" (Karzan, Russia). Almost the same with ASTM D3187-06(2011) Standard Test Methods for Rubber-Evaluation of NBR (Acrylonitrile-Butadiene Rubber)

16. ASTM D6915-12 Standard Practice for Carbon Black-Evaluation of Standard Reference Blacks.

17. Planetary mill "Activator-2S", web site: http://www.activator.ru/ Ac2S.html

18. Kornev, A. E.; Bukanov, A. M.; Sheverdyaev, O. N. Technology of Elastomeric Materials; Scientific Agency of Project and Production "Istek" Ltd.: Moscow, 2000; pp 141-143.

19. Sorbtometr ${ }^{\mathbb{B}}$. Analyzer of a Specific Surface. Web site: http:// catalysis.ru/block/index.php?ID=3\&SECTION_ID=1626

20. Plasti-Corder ${ }^{\circledR}$ Lab-Station http://www.brabender.com/english/ plastics/products.html

21. GOST 270-75 Rubber. Testing of elastic strain properties at stretching (website: http://www.gosthelp.ru/gost/gost21850.html) PDF in attached file

22. Shimadzu. Autograph AG-X plus Series http://www.ssi.shimadzu. com/products/literature/Testing/C224-E053.pdf 23. GOST 426-77 Rubber. Wear resistant testing at sliding (website: http:// www.gosthelp.ru/gost/gost15417.html) pdf in attached file

23. GOST 9.030-74 Uniform system of protection against corrosion and aging. Rubbers. Testing methods on resistance in not tension state to influence of liquid severe environment (website http:// www.gosthelp.ru/gost/gost3586.html)

24. http://www.dvigatel.ru/expo/10865/prod 4705.htm

25. Bergshtein, L. A. Laboratory Workshop on Technology of Rubber; Kchimiya: Leningrad, 1989; pp 66-70.

26. Vostorgnutov, E. G.; Novikov, M. I.; Novikov, V. I.; Prozorovskaya, N. V. Processing of Rubbers and Rubber Blends (rheological bases, technology, equipment); Kchimiya: Moscow, 1980; pp 115116. 